\title{
Presente y futuro de la actividad pericial en las Fuerzas Armadas
}

La actividad pericial en el ámbito Fuerzas Armadas (FAS) ocupa un aspecto destacado dentro de las misiones de la Inspección de Sanidad de la Defensa (IGESANDEF), posicionándose un escalón inmediatamente inferior al apoyo de la FUERZA y por encima de otras actividades como la asistencial, docente o de investigación.

El organigrama de funcionamiento de dicha actividad está basado en dos niveles de atención: el formado por las nueve Juntas Médico Periciales Ordinarias (JMPOs), distribuidas por todo el territorio nacional, y otro, por encima de anterior, constituido por la Junta Médico Pericial Superior (JMPS) y la Junta Médico Pericial Psiquiátrica (JMPP). La dependencia del Inspector General de Sanidad (IGESAN) se establece a través de la Subinspección General de Ordenación Sanitaria. La norma legal que regula su funcionamiento es la Orden PRE/2373/2003, de 4 de agosto, por la que se reestructuran los órganos médico periciales de la sanidad Militar y se aprueban los modelos de informe médico y cuestionario de salud para los expedientes de aptitud psicofísica.

Al igual que ha sucedido en todos los estamentos que integran la IGESANDEF, la actividad pericial se ha tenido que adaptar a la reducción notable de personal facultativo que ha experimentado la Sanidad Militar en los últimos años, y más concretamente desde que los planes de Racionalización (1998) y Modernización (2003) de la Sanidad Militar restructuraron la misma. En la década de los 70 y hasta 1982 se contaba, entre hospitales y clínicas militares de los tres ejércitos, con 58 establecimientos y 14.000 camas, que son aproximadamente las camas públicas que dispone el SERMAS en la Comunidad de Madrid.

La mayor parte de la actividad pericial se desarrolla para dictaminar sobre los expedientes de aptitud psicofísica, según establece la Ley 39/2007, de 19 de noviembre, de la carrera militar, que su artículo 120 señala que «se podrá iniciar un expediente de aptitud psicofísica para determinar si existe insuficiencia de condiciones psicofísicas, a efectos de la limitación para ocupar determinados destinos, según las exigencias que figuren en las relaciones de puestos militares, del pase a retiro o de la resolución del compromiso, según corresponda». El objeto final de la pericia de las distintas JMPOs es la elaboración de un acta basándose fundamentalmente en dos Reales Decretos (R.D): el R.D. 944/2001, de 3 de agosto, por el que se aprueba el Reglamento para la determinación de la aptitud psicofísica del personal de las FAS y el R.D 1971/1999, de 23 de diciembre, de procedimiento para el reconocimiento, declaración y calificación del grado de limitación de la actividad (minusvalía). El primero de estos establece un coeficiente del 1 al 5, y el segundo un grado de discapacidad. La JMPS queda para resolver alegaciones a los dictámenes de las JMPOs así como para coordinar el funcionamiento de dichas Juntas, elaborar estudios y propuestas en materia medico pericial que ordene la Subsecretaría de Defensa y emitir dictámenes médicos para la calificación de incapacidad a efectos de los resarcimientos a víctimas de bandas armadas y elementos terroristas para lo que cuenta con un vocal designado por la Subsecretaría de defensa a instancias del Ministerio de Interior (BOD $n^{\circ} 45$, de 5 de marzo de 2012). Independientemente de estos expedientes de aptitud psicofísica también se elaboran expedientes por fallecimiento, indemnizaciones en operaciones internacionales de paz y seguridad, pensiones aplicando el Reglamento de Comunidades Europeas (E.213) y pensiones de orfandad. Por último, dentro de la actividad pericial, no debemos olvidar del apoyo que se presta en los recursos de responsabilidad civil (patrimonial) y contra dictámenes de incapacidad en Juzgados Militares, Juzgados de lo Contencioso-Administrativo, Juzgados de $1^{\text {a }}$ Instancia e Instrucción y, en su día, en los Juzgados de lo Social.

La actividad de las Juntas, cuando nos referimos a expedientes de incapacidad psicofísica, da lugar a «conflictos de intereses» tanto con las Juntas de Evaluación de carácter permanente de los tres Ejércitos -especialmente con el de Tierra por su mayor volumen- como con el órgano médico pericial de la Guardia Civil. Para las Juntas de Evaluación porque estas consideran que las limitaciones en la actividad que se fijan en el acta, especialmente para los coeficientes 4 (aptos con limitaciones o APL), son incompatibles con un puesto en la estructura del Ejército respectivo. Y con respecto a la Guardia Civil porque la aparición del R.D 401/2013, de 7 de junio que modifica el R.D 944/2001, ha dejado en manos del recién creado órgano médico pericial de la Guardia Civil la decisión de que el interesado permanezca en dicho Cuerpo o bien que pase a retiro. Esto hace que las actas elaboradas por las JMPOs pierdan una parte de su importancia a la hora de la toma de decisiones, dejando que la situación final pueda ser modificada en relación con la posibilidad o imposibilidad de que el interesado siga en activo según el perfil -profesiograma- del puesto de trabajo disponible. El objetivo final es tratar de adaptar los derechos y obligaciones del personal con las necesidades funcionales de las FAS.

Por otra parte, la entrada en vigor del R.D. 13/2010, de 3 de diciembre, de actuaciones en el ámbito fiscal, laboral y liberalizadoras para fomentar la inversión y la creación de empleo, determina en su artículo 20 la inclusión en el Régimen General de la Seguridad Social, a efectos de Clases Pasivas, de los funcionarios públicos y de otro personal de nuevo ingreso a partir del 1 de enero de 2011. Ello implica que el personal militar que haya ingresado a partir de dicha fecha no se beneficiará del trato preferente resultante de la aplicación de la Ley de Clases Pasivas del Estado con las implicaciones económicas que ello supone, ya que será el Instituto Nacional de la Seguridad Social (INSS), a través de cada uno de sus Directores Provinciales, el que determine la situación final de cada implicado.

$\mathrm{Si}$ a la complejidad de la actividad pericial junto con la situación cambiante de la legislación que regula dicha actividad en la Sanidad Militar unimos el incremento de la edad media 


\section{EDITORIAL}

de los componentes de las distintas JMPOs, creemos en la necesidad de la creación de un Instituto Médico Legal de las FAS (IMLFAS). Dicho Instituto funcionaría de modo similar a los Equipos de Valoración de Incapacidades (EVI) del INSS y estaría integrado por rehabilitadores miliares expertos en valoración del daño corporal, así como por psiquiatras militares con una formación específica en la pericia sanitaria. La imposibilidad de centralizar toda la actividad pericial en dicho Instituto -son más de 3000 los peritajes anuales que se realizan- permitiría ir adaptado la probable desaparición, por motivos de pase a la reserva, de algunas JMPOs así como dar la formación necesaria a través de la organización del Master en Valoración del Daño Corporal del que esperamos vea la luz en próxima fechas. El objetivo final es que sea un solo perito el que valore al interesado para evitar la parcelación de su patología y tratar esta en su conjunto, teniendo presente que, desde el punto de vista pericial, la patología no es lo importante sino que son las limitaciones en la actividad que presenta lo que verdaderamente hay que peritar.

Por último, solamente indicar que la profesionalización de la pericia sanitaria a través de la creación del IMPFAS sería la única forma de evitar algo que puede ocurrir en los próximos lustros como es la externalización de una actividad que a lo largo de muchas décadas ha sido una parte consustancial de la Sanidad Militar, seña de identidad de nuestra actividad y espejo de otras actividades periciales fuera de nuestro ámbito.

Rafael Alguacil Rodríguez Coronel Médico

Secretaría de la Junta Médico Pericial Superior de las FAS. Inspección General de Sanidad Gta. del Ejército 1. 28047 Madrid. España 